\title{
Neurologic Outcome of Laminoplasty for Acute Traumatic Spinal Cord Injury without Instability
}

\author{
Hwa Joong Lee, Hwan Soo Kim, Kyoung Hyup Nam, In Ho Han, \\ Won Ho Cho, Byung Kwan Choi \\ Department of Neurosurgery, Medical Research Institute, Pusan National University Hospital, \\ Pusan National University School of Medicine, Busan, Korea
}

Objective: The purpose of this study is to evaluate the efficacy of laminoplasty in the treatment of spinal cord injury (SCl) without instability.

Methods: 79 patients with SCI without instability who underwent surgical treatment in our institute between January 2005 and September 2012 were retrospectively reviewed. Twenty nine patients fulfilled the inclusion criteria as follows: SCl without instability, spinal cord contusion in MRI, cervical stenosis more than $20 \%$, follow up at least 6 months. Preoperative neurological state, clinical outcome and neurological function was measured using the American Spinal Injury Association (ASIA) impairment scale, modified Japanese Orthopedic Association ( $\mathrm{mJOA}$ ) grading scale and Hirabayashi recovering rate.

Results: Seventeen patients showed improvement in ASIA grade and twenty six patients showed improvement in mJOA scale at 6 month follow up. However, all patients with ASIA grade B and C have shown improvement of one or more ASIA grade. Mean Hirabayashi recovery rate was $47.4 \pm 23.7 \%$. There was better neurologic recovery in those who had cervical spondylosis without ossification of posterior longitudinal ligament (OPLL) $\left(p<0.05, X^{2}\right.$ test).

Conclusions: It is different in B, C, D with ASIA A that there are debates going on about the application of surgical treatment in ASIA A, and surgical treatment is helpful in B, C, D since it contributes to neurologic improvement. We concluded that laminoplasty provided good neurologic recovery in $\mathrm{SCl}$ without instability that cervical canal stenosis, especially spondylosis without OPLL and neurologic deterioration in ASIA B, C and D.

Key Words: Laminoplasty $\cdot$ Spinal cord injury $\cdot$ Surgical decompression

\section{INTRODUCTION}

Spinal cord injury (SCI) is a devastating event for the patient and family. The patient may result in permanent disability and the socio-economic impact is a tremendous total.

In the acute post-injury phase, intensive hemodynamic monitoring and critical care management is very impor$\operatorname{tant}{ }^{17,25,27,30)}$. The treatment of SCI without instability such as fracture, dislocation and ligament injury, however, remains controversial.

Additionally, the role and timing of surgical treatment in SCI without instability was debated in several literatures.

- Received: June 10, 2013 - Revised: August 24, 2013

- Accepted: August 26, 2013

Corresponding Author: Byung Kwan Choi, MD

Department of Neurosurgery, Pusan National University Hospital,

305 Gudeok-Ro, Seo-Gu, Busan 602-739, Korea

Tel: +82-51-240-7257, Fax: +82-51-244-0282

E-mail: spine@pusan.ac.kr
Mirza et al,reported that stabilization within $72 \mathrm{hr}$ of injury in cervical spine injured patients is sufficient to improve neurological outcome $\mathrm{e}^{23}$. Other investigators have also reported spontaneous neurological recovery in the conservatively managed group ${ }^{3,428)}$. However, neural compressions by stenotic lesions may warrant surgical interventions to improve paralysis in acute stage. Laminoplasty has been widely accepted as a reasonable option to treat multilevel pathology of the cervical spine, such as OPLL and cervical spondylotic myelopathy (CSM). It permits adequate decompression of the cervical spinal cord and is safe and easily performed ${ }^{16,20,21)}$. The purpose of our study was to evaluate the efficacy of laminoplasty in the treatment of SCI without instability.

\section{MATERIALS AND METHODS}

We retrospectively reviewed the medical records of 79 patients with SCI without instability who underwent surgical treatment in our institute between January 2005 and Septem- 
ber 2012. Twenty nine patients (36.7\%) fulfilled the inclusion criteria as follows: SCI without instability, spinal cord contusion in MRI, cervical stenosis more than $20 \%$, follow up at least 6 months. The spinal cord diameter was measured according to previous authors ${ }^{19)}$,

$$
\frac{(\mathrm{B}-\mathrm{A})}{\mathrm{B}} \times 100 \%
$$

where $\mathrm{A}$ is the diameter of the cervical cord at the injured level and $\mathrm{B}$ is the diameter of the cervical cord at the non-compression level. Exclusion criteria is existence of instability or kyphosis. Cervical spine instability is defined as the loss of ability of cervical spine under physiological loads. Instability was judged by destruction or loss of function of anterior or posterior elements, relative translation of vertebra in sagittal plane higher than $3.5 \mathrm{~mm}$ and angulation higher than $11 \mathrm{deg}$ rees. The degree of cervical instability was assessed by plain film, stress view (flexion and extension), computed tomography (CT) and magnetic resonance image (MRI). There were 26 males and 3 females ranging in age from 31 to 73 years old (mean age 57) (Table 1).

The patients sustained by several different causes of injuries from motor vehicle accident, fall-down and slip down. Preoperative neurological state, clinical outcome and neurological function was measured using the ASIA impairment scale, mJOA grading scale and Hirabayashi recovering rate. Those assessments were made at admission and at 6 month follow-up after surgery.

Table 1. Demographic data of patients

\begin{tabular}{lc}
\hline \hline Category & No. \\
\hline Gender (M/F) & $26(90 \%) / 3(10 \%)$ \\
Mean age (years) & $57 \pm 10.4$ \\
Pre-existing stenotic lesion & \\
Spondylosis & 21 \\
OPLL & 8 \\
Timing of surgery & \\
Within 24 hours & $25(74 \%)$ \\
After 24 hours & $4(26 \%)$ \\
\hline
\end{tabular}

Table 2. Pre- and postoperative neurologic status

\begin{tabular}{cccc}
\hline \hline & Preoperative & Postoperative & $\mathrm{p}$-value \\
\hline ASIA & & & $\mathrm{p}<0.05$ \\
improvement & 3 & 3 & \\
A & 7 & 0 & \\
B & 9 & 6 & \\
C & 10 & 19 & \\
D & 0 & 1 & $\mathrm{p}<0.05$ \\
E & $0-16$ & $0-18$ & \\
mJOA score & $($ Mean $=8.1 \pm 5.3)$ & $($ Mean $=12.1 \pm 5.2)$ \\
& \multicolumn{4}{c}{$47.4 \pm 23.7 \%$} \\
Hirabayashi \\
recovery rate
\end{tabular}

Hirabayashi recovery rate $=\frac{\text { (Post-operative JOA score - Pre-operative JOA score) }}{\text { (Full score - Pre-operative JOA score) }} \times 100 \%$

Statistical analyses were performed using SPSS statistic software $(18.0 \mathrm{~K})$. A p-values were generated using Fisher exact test and repeated measures ANOVA. A p-value of less than 0.05 was considered statistically significant.

\section{RESULTS}

On admission, preoperative ASIA grades were $\mathrm{A}$ in 3, $\mathrm{B}$ in 7, $\mathrm{C}$ in 9 and $\mathrm{D}$ in 10 patients. One patient had both leg weakness with cervical spondylosis before the trauma and the others had no neurologic deficits. Overall pre- and postoperative neurologic status are summarized in Table 2. Preoperative $\mathrm{mJOA}$ scale ranged 0 to $16(\mathrm{Mean}=8.1 \pm 5.3)$ and postoperative mJOA scale ranged 0 to $18($ Mean $=12.1 \pm 5.2$ ). Twenty six patients $(89.6 \%)$ showed improvement in mJOA scale at 6 months follow up. There was statistically significant in improvement of mJOA scale $(\mathrm{p}<0.05$, Repeated measures ANOVA).

Seventeen patients (58.6\%) showed improvement in ASIA grade at 6 months follow up and especially all patients with ASIA grade B and C have shown improvement of one or more ASIA grade (Table 3).

All patients had pre-existing lesion such as degenerative cervical spondylosis or OPLL. Presence of OPLL was confirmed using CT and, especially, type of OPLL was classified on CT sagittal view. This can be seen as areas of ossification behind the cervical vertebral bodies. 21 patients had degenerative cervical spondylosis without OPLL and 8 patients had OPLL. There was better neurologic recovery in those who had cervical spondylosis without OPLL before injury than OPLL ( $\mathrm{p}<0.05$ ) (Fig. 1).

We stratified the patients into two groups according to timing of operative intervention. The early surgical group consisted of 25 patients who underwent surgery within 24 hours of injury. Four patients in the delayed surgical group underwent surgery after 24 hours. The causes of delayed operation were unstable vital sign (1 patient) and hospital visiting over 24 hours ( 3 patients) after trauma. No significant difference

Table 3. Pre- and postoperative ASIA impairment scale

\begin{tabular}{cccccc}
\hline PREOP & A & B & C & D & E \\
\hline A & 3 & 0 & 0 & 0 & 0 \\
B & 0 & 0 & 6 & 1 & 0 \\
C & 0 & 0 & 0 & 9 & 0 \\
D & 0 & 0 & 0 & 9 & 1 \\
E & 0 & 0 & 0 & 0 & 0 \\
\hline
\end{tabular}




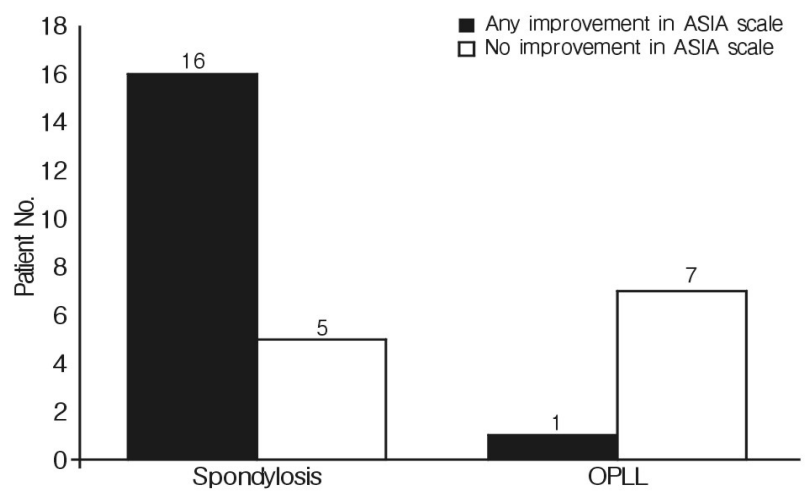

Fig. 1. Neurologic outcome according to pre-existing lesion There was better neurologic outcome in those who had OPLL than other pre-existing lesion before injury $(p<0.05)$.

was noted in neurologic improvement between the early surgical group and delayed surgical group ( $p>0.05)$.

Mean Hirabayashi recovery rate was $47.4 \pm 23.7 \%$. Good neurologic outcome also was noted at short segment ( 2 and 3 levels) laminoplasty in Hirabayashi recovery rate. Hirabayashi recovery rate in 2 and 3 levels laminoplasty group were $66.7 \%$ and $49.4 \%$. However it had no statistical significance.

In this study, 20 patients had spinal cord compression rate, lesser than $50 \%$ and 9 patients' rate was greater than 50\%. A group with compression rate, lesser than 50\% showed better neurologic outcome, however, it did not statistical significance ( $>>0.05$ ) (Fig. 2)

There was no severe postoperative complication but exist some of axial neck pain complaint.

\section{DISCUSSION}

Two major mechanism of spinal cord injury with the neurologic deficits, primary and secondary injuries, are accepted widely ${ }^{1,26}$. The primary mechanism results from an insult that occurs at the time of impact, such compression, distraction, laceration, or shear, which are not amenable to therapy. The secondary injuries, including edema, inflammation, or ischemia, provide a therapeutic window of opportunity for intervention $^{2,12)}$

Although there has been neurological improvement shown with early decompression in animal models ${ }^{6,10)}$, clinical studies on surgical results remain controversial. Various investigators have reported spontaneous neurological recovery in the conservatively managed group ${ }^{3,4,28}$ and conservative treatment remains a good option for patients with incomplete cervical cord injuries $^{18)}$. Kawano et al. reported that surgical treatment was not found to be superior to conservative treatment for cervical spinal cord injury (ASIA B, C) patients without bone and liga-

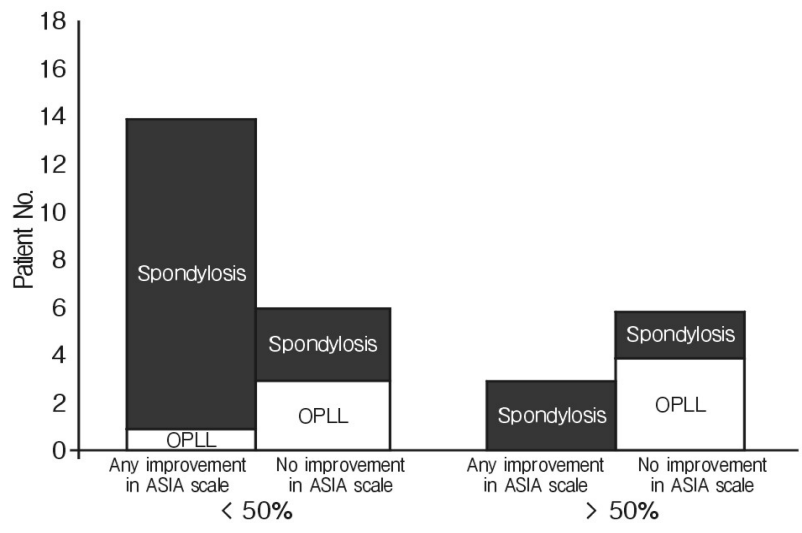

Fig. 2. Neurologic outcome according to cervical stenosis degree Good neurologic outcome was showed at $40-60 \%$ cord compression rate but no significant statically difference $(p \geq 0.05)$.

ment injury in the acute phase ${ }^{19)}$. Therefore some spine surgeons adopted conservative approach. However, the others asserted that operative intervention provided statistically better motor recovery than did conservative therapy ${ }^{5,7}$. In this study, although not compared with conservative treatment, we concluded that surgical intervention, especially laminoplasty, provided good neurologic recovery in SCI without instability.

Some investigators have reported surgical outcome excluded ASIA A and D patients. The reason of exclusion was that many patients with ASIA A were in very poor general condition and either patients with ASIA A or D did not show significant neurologic outcome after surgery. However, in present study, patients with ASIA A and D were included because of presences of cervical cord compressed lesions and contusion. Nevertheless, there were no neurologic recovery in ASIA A and small degree of neurologic recovery in ASIA D. Therefore, surgical treatment might be required in ASIA $\mathrm{D}$, since there was neurologic improvement in some way. However, in ASIA A, it is difficult to make conclusion that it is justifiable to apply surgical treatment since there was no significant neurologic improvement.

The degree of spinal canal stenosis did not affected patients' recovery rate in this study. Although good neurologic outcome showed at lesser than 50\% cord compression rate, neurologic outcome according to the degree of cervical stenosis was no significant statistically difference $(\mathrm{p}>0.05)$. However, Yoo et al reported neurologic deterioration after trauma and outcome after surgery depended on the diameter of the residual spinal canal ${ }^{29)}$.

Chikuda, et al. reported better neurological outcome in patients with gait disturbance before injury when they compared surgery and conservative treatment for traumatic cervical spi- 
nal cord injury associated with OPLL ${ }^{9}$. However, they noted no statistical difference between surgery and conservative treatment ${ }^{9}$. One meaningful result in this study is that there was better neurologic recovery in those who had cervical spondylosis without OPLL before injury than others $(p<0.05$, $\mathrm{X} 2$ test). Although most patients had no neurologic deficits before the trauma, we considered that patients with OPLL had more compressed and vulnerable cord than spondylosis without OPLL. Therefore, patients with OPLL had more neurologic deficits at the time of injury, relatively.

The decompression surgery was anterior approach, posterior approach or both. Fessler et al. reported anterior decompression and fusion provided symptom improvement for CSM ${ }^{15}$. Edwards et al. reported improvement of neurologic symptoms after laminoplasty ${ }^{11)}$. The method of surgical intervention was decided based on pathologic lesion location, range, comorbidity, patient conditions, and operator's favor. Open-door expansile cervical laminoplasty (ODECL) is an effective surgical technique in the treatment of multilevel $\operatorname{CSM}^{16,20,21)}$. This technique was used in multilevel stenosis, no sagittal malalignment and no kyphotic deformities. Laminoplasty may be simpler, more rapid procedure and more effective decompression of cervical spinal canal than anterior decompression in multilevel stenosis. Therefore, we used this laminoplasty in SCI without instability for better neurologic outcome than conservative treatment.

The optimal timing of surgical intervention for spinal cord injury (SCI) remains controversial. Early spinal surgery (within $72 \mathrm{hr}$ after injury) was associated with shorter length of stay and reduced pulmonary complications, however, no differences in neurologic or functional improvements were noted compared with late surgical groups ${ }^{22}$. On the other hand, someone argued early decompression $(<24 \mathrm{hr})$ should be considered as part of the therapeutic management of any patient with SCI, particularly those with cervical SCI ${ }^{13,14,23,24)}$. In our study, no significant difference was noted in neurologic improvement between the early surgical group $(<24 \mathrm{hr})$ and delayed surgical group $(>24 \mathrm{hr})(\mathrm{p}>0.05)$.

Limitation of this study was that there was non-randomized study, bias inherent to retrospective chart reviews, short follow-up period and small sample size. The length of follow up period was less than 1 year in some patients. However, we observed patients' status minimum 6 months, because the neurologic recovery in terms of JOA scores improved after surgical decompression, reached statistical significance at 3 month and reached a plateau at 6 month 8 .

\section{CONCLUSION}

It is different in $\mathrm{B}, \mathrm{C}, \mathrm{D}$ with ASIA A that there are debates going on about the application of surgical treatment in ASIA
A, and surgical treatment is helpful in B, C, D since it contributes to neurologic improvement. We concluded that laminoplasty provided good neurologic recovery in SCI without instability that cervical canal stenosis, especially cervical spondylosis without OPLL and neurologic deterioration in ASIA $\mathrm{B}, \mathrm{C}$ and $\mathrm{D}$.

\section{REFERENCES}

1. AP Amar, ML Levy: Pathogenesis and pharmacological strategies for mitigating secondary damage in acute spinal cord injury. Neurosurgery 44:1027-1039; discussion 1039-1040, 1999

2. DK Anderson, ED Hall: Pathophysiology of spinal cord trauma. Ann Emerg Med 22:987-992, 1993

3. GM Bedbrook: Spinal injuries with tetraplegia and paraplegia. J Bone Joint Surg Br 61-B:267-284, 1979

4. GM Bedbrook, T Sakae: A review of cervical spine injuries with neurological dysfunction. Paraplegia 20:321-333, 1982

5. B Bose, BE Northrup, JL Osterholm, JM Cotler, JF DiTunno: Reanalysis of central cervical cord injury management. Neurosurgery 15:367-372, 1984

6. GD Carlson, CD Gorden, HS Oliff, JJ Pillai, JC LaManna: Sustained spinal cord compression: part I: time-dependent effect on long-term pathophysiology. J Bone Joint Surg Am 85-A:8694, 2003

7. TY Chen, CA Dickman, M Eleraky, VK Sonntag: The role of decompression for acute incomplete cervical spinal cord injury in cervical spondylosis. Spine (Phila Pa 1976) 23:2398-2403, 1998

8. WY Cheung, D Arvinte, YW Wong, KD Luk, KM Cheung: Neurological recovery after surgical decompression in patients with cervical spondylotic myelopathy - a prospective study. Int Orthop 32:273-278, 2008

9. H. Chikuda, A. Seichi, K. Takeshita, S. Matsunaga, M. Watanabe, Y. Nakagawa, et al: Acute cervical spinal cord injury complicated by preexisting ossification of the posterior longitudinal ligament: a multicenter study. Spine (Phila Pa 1976) 36:14531458, 2011

10. JR Dimar, $2^{\text {nd }}$ SD Glassman, GH Raque, YP Zhang, CB Shields: The influence of spinal canal narrowing and timing of decompression on neurologic recovery after spinal cord contusion in a rat model. Spine (Phila Pa 1976) 24:1623-1633, 1999

11. CC Edwards, $2^{\text {nd }}$, JG Heller, DH Silcox, $3^{\text {rd }}$ : T-Saw laminoplasty for the management of cervical spondylotic myelopathy: clinical and radiographic outcome. Spine (Phila Pa 1976) 25: 1788-1794, 2000

12. AI Faden: Experimental neurobiology of central nervous system trauma. Crit Rev Neurobiol 7:175-186, 1993

13. MG Fehlings, D Rabin, W Sears, DW Cadotte, B Aarabi: Current practice in the timing of surgical intervention in spinal cord injury. Spine (Phila Pa 1976) 35:S166-173, 2010

14. MG Fehlings, A Vaccaro, JR Wilson, A Singh, W Cadotte D, JS Harrop, et al: Early versus delayed decompression for traumatic cervical spinal cord injury: results of the Surgical Timing in Acute Spinal Cord Injury Study (STASCIS). PLoS One 7: 
e32037, 2012

15. RG Fessler, JC Steck, M. A. Giovanini: Anterior cervical corpectomy for cervical spondylotic myelopathy. Neurosurgery 43: 257-265; discussion 265-257, 1998

16. K Hirabayashi, K Satomi: Operative procedure and results of expansive open-door laminoplasty. Spine (Phila Pa 1976) 13: 870-876, 1988

17. DA Hovda, DP Becker, Y Katayama: Secondary injury and acidosis. J Neurotrauma 9 Suppl 1:S47-60, 1992

18. S Katoh, WS el Masry, D Jaffray, IW McCall, SM Eisenstein, RG Pringle, et al: Neurologic outcome in conservatively treated patients with incomplete closed traumatic cervical spinal cord injuries. Spine (Phila Pa 1976) 21:2345-2351, 1996

19. O Kawano, T Ueta, K Shiba Y. Iwamoto: Outcome of decompression surgery for cervical spinal cord injury without bone and disc injury in patients with spinal cord compression: a multicenter prospective study. Spinal Cord 48:548-553, 2010

20. TT Lee, BA Green, EB Gromelski: Safety and stability of opendoor cervical expansive laminoplasty. J Spinal Disord 11:12-15, 1998

21. TT Lee, GR Manzano, BA Green: Modified open-door cervical expansive laminoplasty for spondylotic myelopathy: operative technique, outcome, and predictors for gait improvement. J Neurosurg 86:64-68, 1997

22. W McKinley, MA Meade, S Kirshblum, B Barnard: Outcomes of early surgical management versus late or no surgical intervention after acute spinal cord injury. Arch Phys Med Rehabil $85: 1818-1825,2004$
23. SK Mirza, WF Krengel, $3^{\text {rd }}$, JR Chapman, PA Anderson, JC Bailey, MS Grady, et al: Early versus delayed surgery for acute cervical spinal cord injury. Clin Orthop Relat Res:104-114, 1999

24. SM Papadopoulos, NR Selden, DJ Quint, N Patel, B Gillespie, S Grube: Immediate spinal cord decompression for cervical spinal cord injury: feasibility and outcome. J Trauma 52:323-332, 2002

25. CH Tator, EG Duncan, VE Edmonds, LI Lapczak, DF Andrews: Neurological recovery, mortality and length of stay after acute spinal cord injury associated with changes in management. Paraplegia 33:254-262, 1995

26. Charles H Tator: Update on the pathophysiology and pathology of acute spinal cord injury. Brain Pathology 5:407-413, 1995

27. FL Vale, J Burns, AB Jackson, MN Hadley: Combined medical and surgical treatment after acute spinal cord injury: results of a prospective pilot study to assess the merits of aggressive medical resuscitation and blood pressure management. J Neurosurg 87:239-246, 1997

28. CB Wilmot, KM Hall: Evaluation of the acute management of tetraplegia: conservative versus surgical treatment. Paraplegia 24:148-153, 1986

29. DS Yoo, SB Lee, PW Huh, SG Kang, KS Cho: Spinal cord injury in cervical spinal stenosis by minor trauma. World Neurosurg 73:50-52; discussion e54, 2010

30. W Young: The post-injury responses in trauma and ischemia: secondary injury or protective mechanisms? Cent Nerv Syst Trauma 4:27-51, 1987 